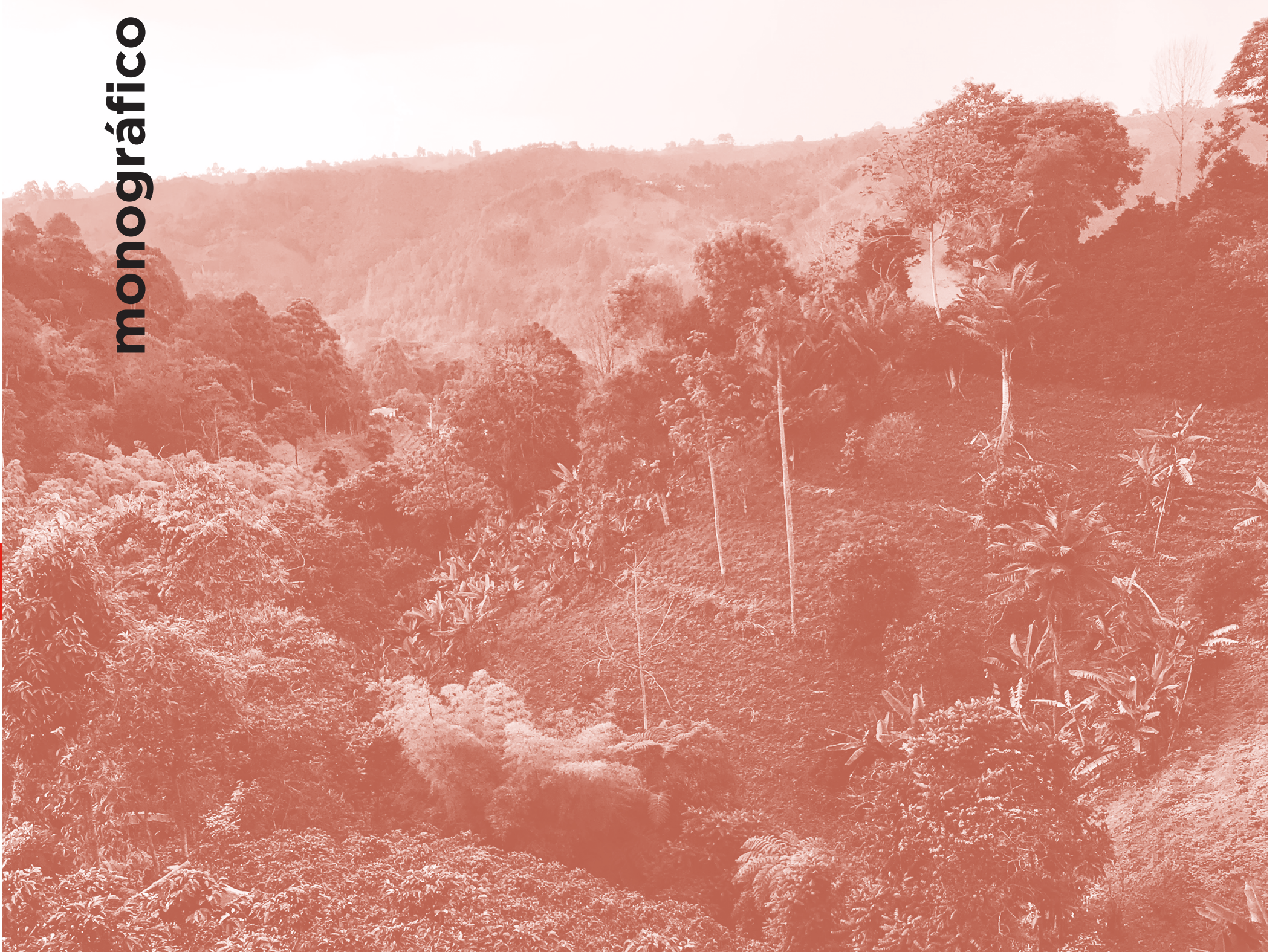

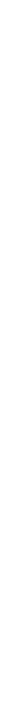




\section{El ministerio en las cumbres}

\section{Germán Rey Beltrán}

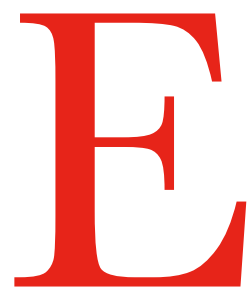

$\mathrm{s}$, ha sido y seguro va a seguir siendo durante muchos años, un referente imprescindible de ministras, ministros y autoridades culturales en regiones y municipios de Colombia. Asesor en el sentido más ancestral de la palabra, quien en la antigua Roma se sentaba junto al juez y le aconsejaba para mirar con amplitud y serenidad antes de juzgar y sentenciar los casos más complejos. Su visión global nos ayuda a viajar por el crecimiento del Ministerio de Cultura, desde su nacimiento en el año 1998, hasta los últimos cambios del año 2019, con avances que en España no hemos logrado, como una ley general de cultura, modélica y que ha servido de referente a muchos otros procesos latinoamericanos. Las diferentes leyes que han ido creciendo al amparo del Ministerio y los aportes de este en los procesos del conflicto colombiano han participado siempre en la búsqueda de una paz repleta de cultura, los desarrollos urbanos, repletos de espacialidad, modos de vivir y nuevos sentidos de incorporar los públicos en el crecimiento de lo privado. Todo resumido con una pluma ágil y conocedora de primera mano de lo que se fragua en el mundo de la cultura actualmente en Colombia.
Una recordada publicidad presentaba a Bogotá como la ciudad 2.600 metros más cerca de las estrellas. Y muchas voces críticas como una ciudad distante y aislada de un país que no conoce. Solo que es la capital de una nación, que como insistía permanentemente el ex Ministro de Cultura, Juan Luis Mejía, está hecha de regiones desconocidas y de diálogos necesarios. No son metáforas inútiles: la institucionalidad fue construida en Colombia a partir del centralismo de la capital y de la simbiosis entre la religión, el poder político y la economía. Y también de la cultura. Esta amalgama de siglos no ha dejado de tener su secuencia en la arquitectura funcional del Ministerio de Cultura de Colombia.

Aún hasta hoy, el vocabulario social utiliza la palabra «territorios», para referirse a lo local y a lo distante. Es una variación más afirmativa que la antigua denominación de los «territorios nacionales», inmensas extensiones de tierras y de poblaciones desperdigadas en medio de selvas y llanuras que conforman media parte de todo el territorio de la nación. Un ejemplo: solo hasta hace dos años, las estadísticas nacionales exploraron la lectura en los territorios para llegar a asombrase de lo que está pasando en ese otro país que desconoce. Por eso la propuesta de Mejía tiene un gran sentido. Sólo hasta hace unos años, a las salas de panóptico del Museo Nacio- 
El Ministerio de Cultura

\section{ha sido un organismo}

\section{importante en la promoción}

\section{de iniciativas para un diálogo}

entre la cultura,

la convivencia y la paz. nal, ocupado por próceres, charreteras y batallas, no habían entrado los exvotos de las comunidades negras del Pacífico ni los melodramas de la televisión. Pero ya lo han hecho, mostrando que es posible reconstruir una visión mucho más completa y plural de un país tan fragmentado como aislado.

\section{La institucionalidad cultural o las premoniciones de los primeros días}

La historia de la institucionalidad cultural colombiana no es muy diferente a la de otros países iberoamericanos. Durante años, el Ministerio de Educación tuvo una División de Divulgación Cultural encargada de los museos, bibliotecas y juntas de organización de festivales y espectáculos populares, así como de las publicaciones culturales y la instrucción física, a la que se agregó una oficina de Extensión Cultural y Bellas Artes y la Sociedad de estudios Arqueológicos.

La composición de la arquitectura cultural no es tampoco otra metáfora inútil. Por el contrario, tiene el poder de la permanencia como si el primer día de la creación, es decir, cuando fueron nombradas y aparecieron las cosas, le insuflara una significación a la comprensión del mundo creado. Hasta hoy, la cultura y sus instituciones guardan, así sea de manera latente, las premoniciones de los primeros días.

La dependencia del Ministerio de Educación dio paso a la creación del Instituto Colombiano de Cultura (COLCULTURA) en 1968 y casi treinta años después, durante el gobierno de Ernesto Samper Pizano, a la creación del Mi- nisterio de Cultura. El nuevo ministerio tuvo la oposición de Gabriel García Márquez, Premio Nobel de Literatura. No era una oposición débil: después de los años sus comentarios tienen la virtud de ser verdades irrefutables, pero también premoniciones fallidas. Al fin de cuentas era un escritor genial y no necesariamente un augur exitoso

La cultura hay que dejarla suelta a su aire, decía en una entrevista de 1994. El Estado tiene el deber de fomentarla y protegerla, pero no de gobernarla, y todo ministerio de cultura termina por ser tarde o temprano un ministerio de policía para la cultura. Un órgano altamente político y perturbador para la comunidad más orgullosa de ser como es: independiente, inconforme, dividida e ingobernable. ${ }^{2}$

Junto a esa afirmación está esta otra:

Sería, además, la apoteosis del centralismo: la cultura de todo el país dirigida desde la cumbre de la Plaza [sic] de Bolívar. La tendencia mundial es la contraria: crear focos descentralizados de desarrollo cultural hasta en los municipios más apartados, que proyecten su acción hacia todas partes. Al fin y al cabo, toda cultura de verdad es popular: nace y crece de la periferia hacia el centro y de abajo hacia arriba. ${ }^{3}$

El nuevo Ministerio de Cultura se debate más en las tensiones de la segunda afirmación que en las dudas de la primera. La Constitución de 1991 tuvo una gran influencia en las comprensiones de la cultura y en el surgimiento del Ministerio. En las comprensiones porque marcó el nuevo mapa constitucional desde la definición de Colombia como un país pluriétnico y multicultural en el que se promueve la cultura, se garantiza su acceso en igualdad de oportunidades, se reconoce la presencia cultural en los planes de desarrollo económico y social, se protege el patrimonio cultural y se defiende la libertad artística. La nueva Constitución señaló la ruta de la gestión ministerial. Y esa ruta comenzó a delinearse en 1997 cuando se promulgó la ley de la cultura que dio paso al ministerio.

Los momentos de esta travesía de veinte años han sido muchos y variados. Primero fue la organización de la estructura del ministerio que siguió el modelo Malraux centrado en las artes, el patrimonio y la difusión cultural. No fue solamente un diseño formal de una arquitectura institucional, sino sobre todo la organización de las comprensiones de 
la cultura en la vida pública de una nación. Pero lo que es más interesante es lo que se puede ver en la flexibilidad que ha tenido el diseño en estas dos décadas, la consistencia de sus ensamblajes y también las fisuras de su materialidad. De las artes se ha pasado a las prácticas artísticas, mientras que el patrimonio inmaterial ha encontrado progresivamente su protagonismo y han aparecido áreas que solo empezaban a insinuarse en los noventa, como por ejemplo, las de poblaciones, industrias creativas y emprendimiento cultural, concertación y fomento. Cada una de ellas inventa sus propias cartografías que pueden ser los grupos étnicos, las lenguas americanas nativas que se hablan en Colombia (cerca de noventa), el manejo de los dineros públicos en la cultura, los sistemas de alianzas público-privadas o las dinámicas culturales de los territorios. Estos rumbos institucionales reemplazaron viejas prácticas del poder cultural e incluso aparentes verdades que tenían pies de barro. Como las asignaciones de dinero público como forma de gratificación y adhesión de las élites culturales, el olvido o aún peor el desprecio de lenguas diferentes al castellano hegemónico, la pérdida de lo cultural en las imposiciones de los mercados apenas adoptaba estructuras industriales o la «naturalización» de las expresiones del patrimonio inmaterial sumergidas en el mágico día a día de la vida corriente.

La reforma más reciente de la estructura del Ministerio se hizo en el 2019 cuando se creó el Viceministerio de Creatividad y Economía Naranja cuyo primer artículo fue «proponer al Ministro las políticas de fomento y estímulo a la creación y a la investigación de la actividad artística y cultural, así como las necesarias para el fortalecimiento de las expresiones culturales y su divulgación en todos los niveles territoriales nacionales y en el exterior». ${ }^{4}$ Fue la adecuación institucional a un programa de gobierno, pero no la reforma más profunda que el Ministerio necesita. Como en muchas otras áreas de la vida del país, las reformas indispensables suelen quedar a medias y convertidas en un peligroso invento más que en su solución.

Un segundo momento fue el desarrollo del Sistema Nacional de Cultura, ${ }^{5}$ establecido por la Ley 397 de 1997 (Ley General de Cultura) que lo define como

el conjunto de instancias y procesos de desarrollo institucional, planificación e información articulados entre sí, que posibilitan el desarrollo cultural y el acceso de la comunidad a los bienes y servicios culturales según los principios de descentralización, participación y autonomía.
En estas dos décadas la gestión pública de la cultura ha tenido el apoyo de los Consejos Nacionales, departamentales y municipales de cultura que conforman un tejido de análisis, discusión y aporte al funcionamiento de las políticas públicas de cultura. Es uno de los mecanismos que intenta hacer realidad lo que Gabo afirmó en su entrevista: que la cultura crezca de la periferia hacia el centro y «de abajo hacia arriba». Sin embargo el sistema sufre de los males de su propia condición: es formal, atrae a los representantes del sector de la cultura afianzando el corporativismo y no logra incorporar a un número importante de ciudadanos, especialmente los más jóvenes, que se mueven con mayor facilidad en el entretenimiento y las tecnologías. Mientras que la democracia representativa se replantea seriamente en el mundo y ensaya formas novedosas de participación, los ministerios persisten en figuras formales que se van tornando anacrónicas e ineficientes. Pero aún a pesar de sus limitaciones, sería una pérdida no tenerlo.

Las políticas culturales son un tercer momento del desarrollo de la acción del Ministerio de Cultura de Colombia. Cuando en el 2010 la ministra Paula Marcela Moreno Zapata propuso llevar a cabo un Compendio de Políticas culturales $^{6}$, se encontraron políticas formuladas hace años y se emprendió un trabajo tanto de recuperación - quizás de los más fructíferos en los años recientes - como de actualización y de definición de otras políticas que eran necesarias y debían agregarse al panorama de las construidas durante décadas. Las unas testimonian la historia de lo avanzado y las otras los nuevos horizontes de la cultura, y entre las dos se observan las dimensiones de los cambios que se han dado en la vida cultural de los colombianos. El listado reunía las Políticas de artes, la de gestión, protección y salvaguardia del patrimonio cultural e inmaterial, la de museos, la de archivos, la de protección a la diversidad etnolingüística, las de diversidad cultural, de turismo cultural, de lectura y bibliotecas, de comunicación/cultura, de cultura digital y cinematográfica, la del emprendimiento y las industrias culturales, la de concertación, de estímulos, de infraestructura cultural, de gestión internacional de la cultura y de casas de cultura.

Cada una ameritaría un análisis de su desarrollo y repercusiones. Sin embargo, conviene destacar los grandes esfuerzos que ha hecho Colombia en la promoción de los libros, la lectura y las bibliotecas en un proyecto coordinado operativamente por la Biblioteca Nacional y articulado muy cercanamente con las Secretarías de Cultura de los departamentos y los municipios, que ha logrado configurar una potente red de bibliotecas públicas que abarca toda la geo- 
grafía del país y que ha incidido en los índices de lectura que aún son bajos. Colombia ha tenido desde hace años una preocupación por el tema: la República Liberal de los años treinta promovió un gran interés por las culturas populares, una relación estrecha entre lectura, educación y entretenimiento, una biblioteca aldeana que intentaba romper con las limitaciones de la divulgación del libro y una interacción pionera entre la lectura y el cine.

A esta tarea y a muchas más realizadas posteriormente se unen hoy los procesos de digitalización de las bibliotecas, el fortalecimiento de redes como Bibliored en Bogotá y el Sistema público de Bibliotecas en Medellín, la inversión pública en dotación, la formación de bibliotecarios, la promoción de proyectos populares de lectura como "Libro al viento" o los PPP, la generación de planes consistentes de promoción del libro y la lectura, el fortalecimiento de las bibliotecas escolares por parte del Ministerio de Educación y la preocupación por nuevos modos de lectura, especialmente los que circulan a través de los soportes digitales. ${ }^{7}$

Las leyes y políticas de cine han sido decisivas en el desarrollo de la cinematografía nacional al impactar en el número de películas colombianas producidas por año, en su circulación y premiación en reconocidos festivales internacionales, en la promoción de los estímulos para los diferentes momentos de su cadena productiva, en la consolidación de la labor de proimágenes y del fondo para el desarrollo cinematográfico que administra la entidad en el crecimiento de los centros de formación de cine, y en la tarea de conservación, memoria y divulgación del cine nacional junto a la cualificación de la reflexión y las investigaciones sobre la cinematografía local. Hay problemas detectados en el crecimiento de los espectadores del cine colombiano, en la superación de problemas de circulación y participación de cine producido en las regiones, en la formación en determinados oficios que tienen importancia en el proceso de producción o en el soporte financiero y tecnológico de las realizaciones audiovisuales. En una medición llevada a cabo por el Ministerio de Cultura de los datos aportados por la cuenta satélite de cultura se encontró que el sector más activo de la economía cultural y creativa colombiana es el audiovisual ampliado, es decir, que contempla además del cine, la televisión, la radio y los nuevos medios. ${ }^{8}$

Aunque ha tenido poca influencia en la industria televisiva nacional, el ministerio de Cultura creó una dirección de comunicaciones que ha estado atenta a esas otras formas de realización audiovisual que no pasan necesariamente por las lógicas y las decisiones del mercado, estimulando a los creadores independientes, los jóvenes en las regiones y los pequeños emprendimientos de vídeo y de televisión local.

El interés por las industrias culturales y creativas ha crecido en Colombia, jalonado por la televisión, la industria editorial, el cine, la música, las artesanías, el diseño, la moda, la cocina y los nuevos medios. El panorama de las industrias creativas colombianas ha estado marcado por su asimetría y el desarrollo desigual, el predominio de la industria audiovisual, la concentración geográfica de la producción, la debilidad de las empresas regionales, los problemas de sostenibilidad y las dificultades de la distribución de sus productos. Pero han sido industrias que han tenido fuentes originales y diversas de creación, conexiones muy interesantes con procesos sociales de identidad y diversidad cultural capaces de mantenerse en tiempos y condiciones dificiles y sentido de la innovación. La promulgación de la Ley Naranja en el Congreso y la incorporación de la Economía Naranja al gobierno de Iván Duque son hechos que se deben destacar pero a la vez mirar críticamente. Sobre todo en lo que concierne a la conexión de la economía cultural y creativa con el desarrollo sostenible, su capacidad de inclusión, el apoyo a la diversidad cultural, la promoción de emprendimientos regionales y locales, la desconcentración, la formación de todos los oficios involucrados en las cadenas de valor y las conexiones con lo patrimonial, las culturas populares y las nuevas formas de experimentación e innovación.

\section{Cultura, etnias y convivencia}

El conflicto, la paz y la cultura es una tríada muy importante en Colombia, un país que ha vivido una profunda tragedia cultural por más de medio siglo y que se ha manifestado en el desplazamiento forzado, la inmensa cantidad de víctimas, la vulneración de derechos de grupos indígenas, afrocolombianos y raizales, el silenciamiento de manifestaciones expresivas de las comunidades y la ruptura violenta de lazos identitarios. En el Acuerdo de paz firmado en el 2016 entre el Estado colombiano y la guerrilla de las FARC, hay un conjunto de comprensiones de la cultura relacionados con los derechos humanos, el territorio, los enfoques diferencial y de género, los medios de comunicación comunitarios y la construcción de una cultura de paz que se espera de las diferentes instancias de la Justicia Especial para la Paz una presencia fundamental en el restablecimiento de los derechos y las realidades culturales de quienes fueron afectados directa e indirectamente por el largo y degradado conflicto colombiano.

El Ministerio de Cultura ha sido un organismo importante en la promoción de iniciativas para un diálogo entre 


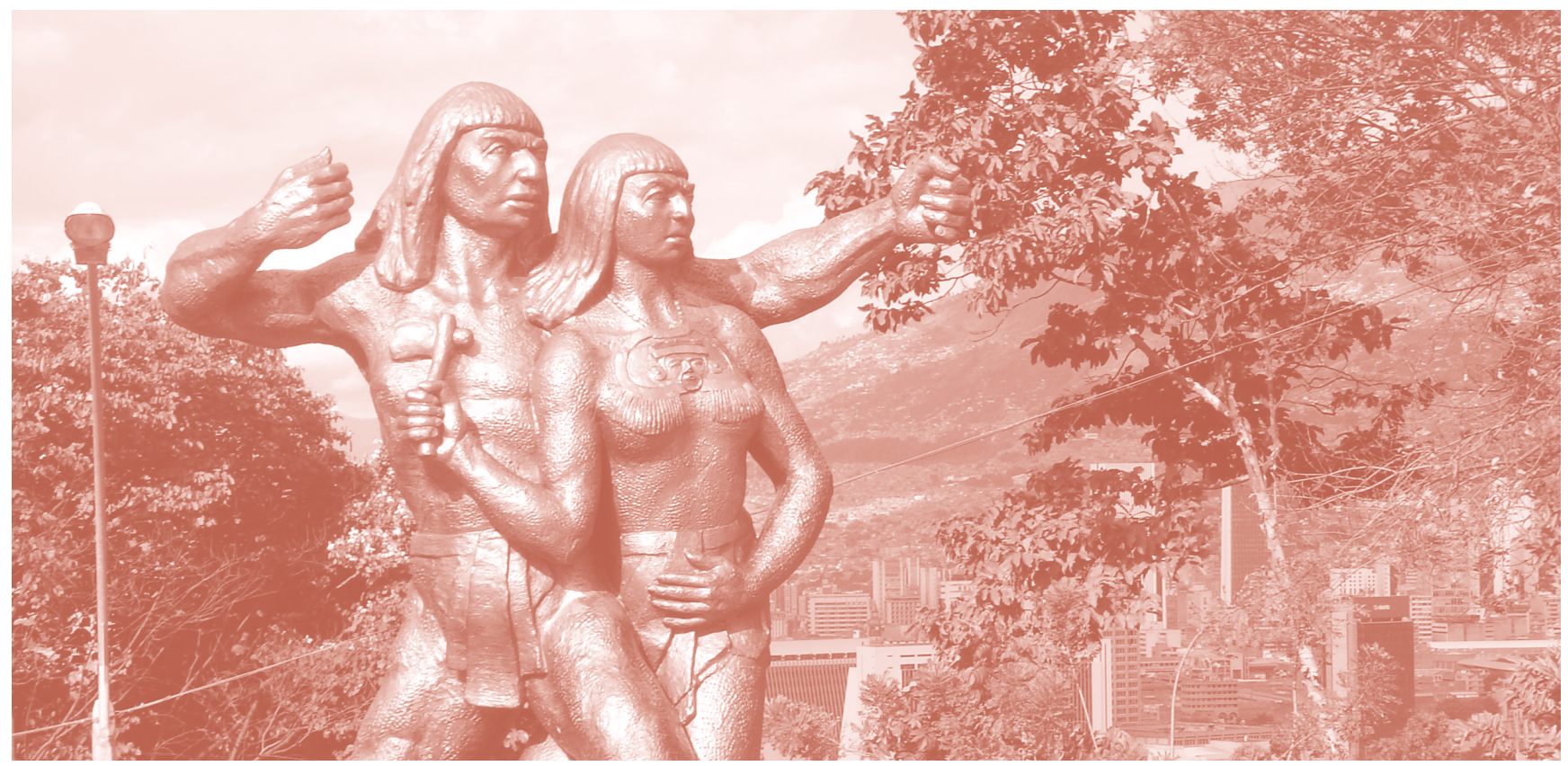

la cultura, la convivencia y la paz. Los proyectos llevados a cabo por la Fundación Batuta son un ejemplo de la presencia de la música en zonas de conflicto a través de la formación musical de niños, niñas y jóvenes apoyado por el Ministerio y otras instituciones públicas y privadas.

Colombia es un país en que culturalmente hay una presencia destacada de comunidades indígenas, grupos afroamericanos, raizales y gitanos. Pero también $-\mathrm{y}$ debe decirse - en que estos grupos han sido excluidos, estigmatizados y perseguidos. No son solo persecuciones antiguas. Durante años han estado en el centro del huracán del conflicto, asolados por diferentes tipos de victimarios: desde los narcotraficantes, guerrillas, paramilitares y bandas criminales hasta algunos agentes del propio Estado. Si se abre un periódico de estos días se pueden observar carteles, disidencias y guerrillas que combaten en sus territorios por el dominio de los pasos del narcotráfico, los cultivos ilícitos y los laboratorios de procesamiento de todo tipo de estupefacientes o de latifundistas voraces interesados por el robo de sus tierras. A lo que los indígenas responden con sus mingas, formas de justicia tradicional y muertos.

Desde las movilizaciones de los buques esclavistas europeos hasta hoy, los afrocolombianos han sido víctimas de la pobreza, la exclusión y la desatención. Algunas de las zonas más abandonadas del país están habitadas por asentamientos de comunidades negras que no parecen vivir mejor que sus antepasados esclavizados. Sin embargo subsisten en medio de una inmensa paradoja: junto a la pobreza está una de las mayores biodiversidades del planeta y al lado de la violencia algunos de los lugares más ricos para la extracción minera. Y con ellos un rico paisaje de expresiones artísticas y patrimoniales.

Uno de los temas interesantes en la gestión del ministerio ha sido su apertura hacia un diálogo cada vez más consistente y creativo con otras áreas de la vida social y la gestión pública. Hoy son más frecuentes las interacciones con temas de salud, justicia, medio ambiente o planificación y vida urbana. Las tecnologías han abierto conversaciones impensables hace años con las artes hasta el punto de hablar de cultura digital y de comprobar que algunas de las manifestaciones culturales más destacadas cada vez pasan más por los nuevos soportes digitales. Los planes de ordenamiento territorial, es decir, el diseño de las ciudades hacia el futuro, han encontrado que la cultura es fundamental no solo para estudiar sus equipamientos o las disposiciones de los distritos creativos, sino para el encuentro entre la espacialidad, los modos de vivir, la movilidad y los nuevos sentidos de lo público. Y esto ha generado, por una parte, que el «reino» de la cultura se divida y a la vez, se multiplique. Los territorios cerrados de lo cultural se amplían, convirtiendo estos diálogos intersectoria- 
les en fronteras porosas mientras que los dominios hegemónicos se fracturan y los márgenes empiezan a ser significativos y considerados. Lo cultural está también en el Ministerio de las tecnologías de la información y la comunicación en donde se generan instancias para los proyectos de creación, las intervenciones comunicativas en las zonas rurales y en los barrios (a través de programas como Vive Digital), las radios comunitarias y los medios informativos digitales y los modos de apropiación cultural de las nuevas tecnologías.

\section{Cumbres y periferias en la cultura}

Las cumbres en las que habitan los ministerios suelen ser centrales. Pero cumbres (por lo menos, en el caso colombiano) hay por todas partes. Vencer esta centralidad geográfica y política ha sido difícil a pesar de los continuos esfuerzos. Algunos de ellos han fracasado porque todo se reduce a una suerte de ritual de mímesis en el que la apariencia le gana la partida a la veracidad. Las políticas continúan centralizadas y operan verticalmente, la participación se canaliza hacia los centros del poder y los procesos de desarrollo son atraídos de manera inexorable por los polos de la concentración cultural. Entretanto las dinámicas regionales no son lo suficientemente fuertes para producir dislocaciones de esta «atracción fatal», con excepción de unas pocas que ya tienen una significativa vida propia. Lo que llama, sin embargo, la atención es la enorme diversidad y persistencia de pequeñas y medianas experiencias culturales y artísticas que se encuentran desperdigadas por todo el territorio nacional y que en trabajos anteriores he llamado «las dinámicas del hormiguero» ${ }^{9}$ retomando el concepto de Michel de Certeau que insistía en que «la cultura está en los márgenes», o el papel de las hormigas que destacaba Clifford Geertz al comienzo de su obra Conocimiento local cuando acudía al aforismo africano que nos recuerda que «La sabiduría está en el conjunto de las hormigas».

El hormiguero cultural en Colombia es amplio y diverso. Un país que tiene más de medio millar de emisoras de radio comunitaria y cerca de novecientos medios digitales informativos es un fenómeno para estimar. Si a ellos se junta la gran cantidad de fiestas, festivales populares y carnavales, colectivos de jóvenes entusiasmados por la creación, proyectos locales de memoria, grupos de teatro, pequeñas editoriales independientes y conjuntos de música, se tiene un panorama invaluable.

Las hormigas sobreaguan entre problemas de sostenibilidad, necesidades de formación, garantías de estímulo y adecuaciones a las oscilaciones, en ocasiones muy agresivas, del entorno social y político.
Una buena parte de estas «experiencias de hormiguero» existen en zonas muy difíciles, que durante años han estado cercadas por diferentes actores que dominan el territorio por las armas y por los negocios exorbitantes provenientes del narcotráfico, la minería extractiva, el despojo de tierras o la corrupción. Muchas veces viven en medio de ambientes de «extremófilos», incidiendo en la convivencia, el desarrollo de la imaginación, la persistencia de la memoria o el ejercicio de la solidaridad de sus comunidades de proximidad. Esas zonas pueden ser territorios aislados o por el contrario barrios de las grandes ciudades que tienen fronteras invisibles, comunidades enclavadas en zonas cocaleras o pueblos en medio de lugares de tránsito en que actores luchan por su dominio, grupos humanos en regiones con una gran tradición y riqueza cultural o habitantes urbanos conectados con las transformaciones digitales y los flujos creativos internacionales.

Uno de los logros del Ministerio de Cultura de Colombia durante estos años ha sido el trabajo persistente en materia de información cultural. Lograrlo en medio de la fragmentación, las distancias geográficas y las tensiones internas tiene un cierto matiz épico que rodea a algunas de las grandes creaciones culturales colombianas. De manera concertada con la entidad que maneja las estadísticas nacionales (DANE) se tiene una información tan consistente como valiosa sobre los proyectos de desarrollo cultural, el consumo y la apropiación, los hábitos de lectura, el acceso a las nuevas tecnologías y la vertiginosa aculturación digital. Lo interesante es que estos datos han sido recogidos en los últimos veinte años y permiten llevar a cabo estudios históricos y análisis longitudinales. También posibilitan un nivel de comparación de las prácticas culturales y artísticas tal como son asumidas por los colombianos y de contraste con lo que pasa en la región y en general en el mundo. Desde finales de los noventa, Colombia tiene información sobre las relaciones entre economía y cultura, ha estructurado una cuenta satélite de cultura, tiene sistematizada la información sobre inversión estatal en cultura y estudios de econometría que exploran las repercusiones que han tenido algunas de sus políticas culturales más destacadas de las dos últimas décadas (por ejemplo la de cine y la de lectura y bibliotecas). A ello se agrega la información especializada en cada uno de los sectores de la cultura como la música, el cine, algunos centros históricos y las fiestas y carnavales.

El talón de Aquiles de los Ministerios de Cultura es su presupuesto en varios aspectos: en su monto total anual, en su relación con las asignaciones presupuestales generales de los gobiernos y en su distribución en programas y apo- 
yos. En el caso colombiano, el presupuesto de cultura ha sido permanentemente el más bajo. Sin embargo no siempre ha sido así. El gobierno del alcalde de Medellín Sergio Fajardo lo aumentó a un 4\% en un claro gesto de voluntad política.

Varias leyes de la cultura tienen interesantes estrategias fiscales como la ley del libro, la ley del cine, la ley de la economía naranja y la ley de espectáculos públicos. Los recursos provenientes del Impuesto Nacional al ConsumoINC (anteriormente Impuesto al Valor Agregado- IVA), a la tarifa del $4 \%$ al servicio de la telefonía móvil, son una de las fuentes de financiación a la cultura. Pero aún hay un camino por recorrer en la búsqueda de recursos a través de las alianzas público-privadas y el mecenazgo.

En uno de sus diarios Alexander Von Humboldt describe su llegada a Santafé de Bogotá así:

Los ojos están acostumbrados a los espesos bosques, precipicios y montes rocosos y de repente ve ilimitados campos de trigo en la planicie sin árboles. Y exactamente a esa altura, a la altura de los más altos Pirineos, el Canigou, en esa atmósfera encarecida han levantado los hombres una gran ciudad...

Casi dos siglos después, Gabriel García Márquez propuso una imagen de pesadilla para oponerse a la existencia del Ministerio de Cultura. En su imaginación, la apoteosis del centralismo sería: «la cultura de todo el país dirigida desde la cumbre de la Plaza [sic] de Bolívar». Aunque aún ande por las cumbres de este país andino y haya reconocido en parte la importancia de una cultura venida desde abajo, el futuro del Ministerio de Cultura está, como lo señaló nuestro escritor, mucho más del lado de las periferias.

\section{Notas}

(1) Profesor en la Maestría en Comunicación de la Pontificia Universidad Javeriana. Ha sido asesor del proyecto de Economía y Cultura del Convenio Andrés Bello, del Ministerio de Cultura de Colombia y de la Secretaria de Cultura, Recreación y Deporte de Bogotá. Participó en el Plan de Desarrollo cultural de Medellín y fue el coordinador del Compendio de Políticas culturales del Ministerio de Cultura de Colombia (2010). Ha participado en proyectos culturales de la UNESCO, la AECID, la SEGIB, la OEA y la OEI. Miembro de la Junta Directiva de FUNDALECTURA, del FOTOMUSEO y la Fundación Gabo de Nuevo Periodismo Iberoamericano.

(2) "Gabo se opone a Mincultura", Bogotá, El Tiempo, 6 de Julio de 1994.

(3) óp. cit.

(4) Decreto 2120 de 2018 por el cual se modifica la estructura del Ministerio de Cultura.

(5) Sanabria, A. (2000): Ley general de cultura, Bogotá, Ministerio de Cultura.

(6) Rey, G. (2010): Compendio de Políticas culturales, Bogotá, Ministerio de Cultura.

(7) VV. AA. (2013): Hábitos de lectura, asistencia a bibliotecas y consumo de libros en Colombia, Bogotá, Fundalectura, Ministerio de Cultura, Ministerio de Educación, Ministerio de tecnologías de la Información y las Comunicaciones DANE, Cerlalc, Cámara Colombiana del Libro, Secretaría Distrital de Cultura, Recreación y Deporte.

(8) Cultura a la medida. Análisis de la Cuenta Satélite de Cultura de Colombia, Bogotá, Ministerio de Cultura, 2015.

(9) Martinell, A. (coord.) (2010): "La insistencia en la metáfora. Experiencias locales de cultura y desarrollo en Colombia" en Cultura y Desarrollo, Madrid, Fundación Carolina, Siglo XXI, págs. 181-208 y Rey, G. (2018): "La vida en el hormiguero", Revista ARCADIA, Bogotá, nº 154. 